\title{
Refractoriness to melatonin and short daylengths in early seasonal quiescence in the Bennett's wallaby (Macropus rufogriseus rufogriseus)
}

\author{
A. S. I. Loudon and J. D. Curlewis \\ M.R.C./A.F.R.C. Comparative Physiology Research Group, Institute of Zoology, \\ Zoological Society of London, Regents Park, London NWI 4RY, U.K.
}

\begin{abstract}
Summary. Adult female Bennett's wallabies were treated with reductions in daylength, melatonin implants or injections of melatonin $2 \mathrm{~h}$ before dusk in early or mid-seasonal reproductive quiescence. In early reproductive quiescence ( 5 weeks after the winter solstice) reproductive quiescence did not end in response to 3 or $5 \mathrm{~h}$ of reduced daylength or in response to injections $(400 \mathrm{ng} / \mathrm{kg})$ or implants $(0.5 \mathrm{~g}$ in a Silastic rubber envelope) of melatonin. Reductions in daylength at this time of year did, however, result in an extension of the circadian pattern of melatonin secretion. In mid-reproductive quiescence ( 21 weeks after the winter solstice) treatment with a $5 \mathrm{~h}$ reduction in daylength, melatonin injections administered $2 \mathrm{~h}$ before dusk or melatonin implants did result in the termination of reproductive quiescence and reactivation of the quiescent corpus luteum within a period of 5 days. The results of these experiments indicate that, in early reproductive quiescence, the Bennett's wallaby is refractory to the influence of reduced daylength or melatonin, although capable of responding to such reduced days in terms of an increased duration of melatonin secretion. Bennett's wallabies therefore exhibit a refractoriness to short days similar to that of some seasonal eutherians although it remains to be established whether this refractory response is the cause of the transition to seasonal reproductive quiescence.
\end{abstract}

\section{Introduction}

Bennett's (Macropus rufogriseus rufogriseus) and tammar (Macropus eugenii) wallabies exhibit the phenomenon of seasonal embryonic diapause (Berger, 1966; Merchant \& Calaby, 1981). In both species, the breeding season begins soon after the summer solstice (tammar: Andrewartha \& Barker, 1969; Flint \& Renfree, 1982; Bennett's wallaby: Merchant \& Calaby, 1981; Fleming et al., 1983) and extends to the winter solstice in the tammar (Tyndale-Biscoe et al., 1986) or up to 10 weeks after the winter solstice in the Bennett's wallaby (Curlewis et al., 1987). Birth is followed by oestrus and the resulting conceptus develops to the unilaminar blastocyst stage. During the breeding season, the suckling stimulus of the pouch young maintains the corpus luteum (CL) in a quiescent state and hence prevents the implantation and development of the blastocyst (lactational quiescence; Merchant, 1979; Merchant \& Calaby, 1981). Removal of the pouch young during the breeding season results in reactivation of the quiescent CL and blastocyst and birth follows 27 days later (Merchant, 1979; Merchant \& Calaby, 1981). After the breeding season, the removal or loss of the pouch young does not result in reactivation of the quiescent $C L$ and the animal remains in a state of seasonal quiescence.

During seasonal quiescence in the tammar, artificial transfer from long to short days is effective in prematurely terminating seasonal quiescence (Sadleir \& Tyndale-Biscoe, 1977; Hinds \& den Ottolander, 1983) and it appears that changes in the nocturnal melatonin profile mediate this 
response (McConnell \& Tyndale-Biscoe, 1985). Treatment with melatonin by injection $2 \mathrm{~h}$ before dusk (tammar) or by subcutaneous implant (Bennett's wallaby) mimics the effects of artificial reductions in daylength and results in the premature termination of seasonal embryonic quiescence (McConnell \& Tyndale-Biscoe, 1985; Loudon et al., 1985). In all of these experiments in the tammar wallaby, animals have been pre-treated with artificial long days before treatment with melatonin or daylength reduction. However, seasonal diapause begins while daylengths are still short and for this time of year there is no information available as to the effect of melatonin or daylength reductions on embryonic diapause. In seasonal eutherians, a response to reductions in daylength or exogenous melatonin cannot occur before the animal has been exposed to a critical number of long days. For instance, in the ram, exposure to long days is necessary before rams can respond to melatonin implants (Lincoln \& Ebling, 1985) while in the ewe, treatment with melatonin in January (Nett \& Niswender, 1982) or April and May (Nowak \& Rodway, 1985; English et al., 1986) is ineffective in inducing an early return to oestrus. In contrast, treatment with melatonin close to or after the midsummer solstice is effective in inducing early breeding in the ewe (Kennaway et al., 1982; Arendt $e t$ al., 1983) and in seasonal deer (Bubenik, 1983; Adam \& Atkinson, 1984; Lincoln et al., 1984). In this paper, we report the results of experiments designed to consider the effect of reductions in daylength or treatment with melatonin 1-2 months and 4-5 months after the winter solstice on the seasonal reproductive quiescence in the Bennett's wallaby.

\section{Materials and Methods}

Animals. Adult lactating Bennett's wallabies were removed from the breeding colony at Whipsnade and housed at the Institute of Zoology under husbandry conditions described elsewhere (Curlewis et al., 1986).

Experiments $1(a)$ and $I(b)$ : the effect of exposure to very short daylengths $I-2$ months after the winter solstice. The design of this and subsequent experiments is indicated in Fig. 1. In Exp. 1(a), 6 females with pouch young were housed in the presence of a male in early January 1985 . On 14 January, all pouch young were removed and on 22 January the animals were housed in a light chamber and exposed to an artificial lighting regimen designed to simulate the natural photoperiod at that time of year (simulated natural daylength). The duration of daylength was determined from the Royal Greenwich Observatory Tables and $40 \mathrm{~min}$ per day was added as an equivalent to civil twilight $(9 \mathrm{~h}$ of light: $15 \mathrm{~h}$ of dark [9L:15D]) from 14 to 26 January with lights on at $07: 35 \mathrm{~h}$ (GMT). From 26 January to 4 February, 15 min of additional lighting was added per day (9.25L:14.75D) to allow for changes in daylength after the winter solstice. For part of the period when lights were switched on, animals were allowed access to an outside yard but animals were shut into the light chambers at least $1.5 \mathrm{~h}$ before the time of lights off in the chamber. Lighting was provided with Osram cold white strip lights. Light levels were determined with an LMP 1000 Luminance meter (R \& B Research Devices, London, U.K.) calibrated against a barium sulphate-based Eastman Kodak White standard. The levels of illuminance measured from light levels reflected from the walls was $160( \pm 21$ s.e.m., $n=6)$ lux. Direct measures of illuminance of the bulbs were in excess of 800 lux. A $10 \mathrm{~W}$ photographic bulb provided dim red illumination $(<0 \cdot 3$ lux $)$ continuously throughout the 24-h period.

From 4 February, daylength was reduced by $3 \mathrm{~h}$ per day $(6 \cdot 25 \mathrm{~L}: 17 \cdot 75 \mathrm{D}$; reduced daylength). After 2 weeks, animals were returned to conditions of natural ambient photoperiod. Pouches were checked daily for the presence of a neonate from Day 26 after removal of pouch young and females were examined for signs of a copulatory plug. On 25 January (simulated natural daylength) blood samples were collected for the determination of melatonin concentration in plasma at hourly intervals from $15: 30$ to $19: 30 \mathrm{~h}$, a single sample was taken at 24:00 h and then hourly samples taken from $04: 30 \mathrm{~h}$ to $08: 30 \mathrm{~h}$ the following day. On 14 February (reduced daylength) samples were collected at hourly intervals from 13:00 h to $17: 00 \mathrm{~h}$, a single sample taken at $22: 45 \mathrm{~h}$ (the mid-point of the dark phase) and then hourly samples taken from $04: 30 \mathrm{~h}$ to $09: 30 \mathrm{~h}$ the following day.

In Exp. 1(b), 6 lactating females and 1 adult male were moved on 29 January 1986 to the light chamber described above and pouch young were removed the same day. The animals were exposed to the same pattern of simulated natural photoperiod described above from 29 January to 11 February with the exception that $1 \mathrm{~h} 14 \mathrm{~min}$ per day was added as equivalent to civil twilight. On 11 February, daylength was reduced by $5 \mathrm{~h}$ (lights on 09:19 h, off $15: 11 \mathrm{~h}$ GMT). On 25 February animals were returned to conditions of natural ambient photoperiod. Serial blood samples were collected for the determination of plasma melatonin concentration on 10 February (simulated natural photoperiod) at 2-h intervals from 12:00 h to 12:00 h the following day. On 25 February (after a $5 \mathrm{~h}$ reduction in daylength) blood samples were collected at $2-\mathrm{h}$ intervals over the same time period. As a control, a further 6 females and an adult male were kept in conditions of natural photoperiod and temperature and pouch young were removed on 5 February. From 6 February to 27 March, blood samples were collected from all animals between $09: 30 \mathrm{~h}$ and $11: 30 \mathrm{~h}$ for the determination of progesterone concentration in plasma. 


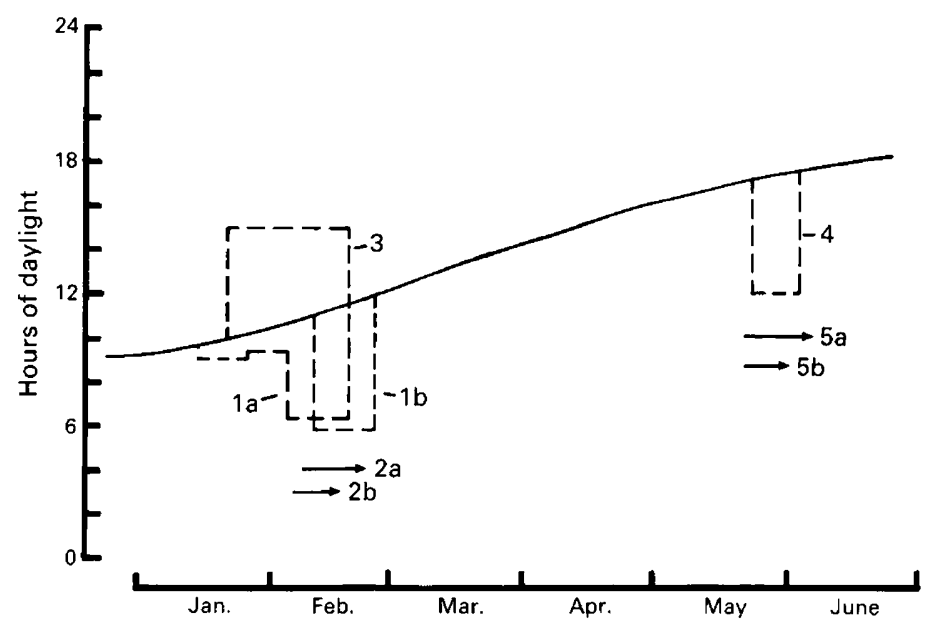

Fig. 1. The design for Exps 1-5. In Exps 1(a) and 1(b) (February 1985 and 1986 respectively), a pattern of simulated natural photoperiod was followed by a reduction in daylength of 3 and $5 \mathrm{~h}$ respectively for a period of 2 weeks. The duration of treatment with melatonin implants and pre-dusk daily injections in February is shown as a continuous line for Exps 2(a) and 2(b) respectively. In Exp. 3 (February 1985), animals were exposed to an increase in photoperiod of $5 \mathrm{~h}$ for a 4 -week period, followed by a return to natural daylength. In Exp. 4 (May 1985), animals were exposed to a $5 \mathrm{~h}$ reduction in photoperiod for a 2 -week period. The duration of melatonin treatment in Exps 5(a) and 5(b) (May 1985) is shown as a continuous line for melatonin implants and pre-dusk daily injections respectively.

Experiments 2(a) and 2(b): the effect of melatonin 1-2 months after the winter solstice. In Exp. 2(a), 6 lactating females and an adult male were housed under natural photoperiod and temperature from early January 1985 . On 25 January, pouch young were removed (Day 0) and on 7 February (Day 13) all females were sedated with $300 \mathrm{mg}$ ketamine (Parke, Davis and Co., Pontypool, Gwent, U.K.) and $70 \mathrm{mg}$ xylazine (Bayer UK Ltd, Bury St Edmonds, Suffolk, U.K.) and 0.5 g melatonin (Sigma Chemicals, Poole, Dorset, U.K.) in a Silastic rubber envelope (surface area $7 \mathrm{~cm}^{2}$; Dow Corning, Midland, Michigan, U.S.A.) was implanted subcutaneously. Blood samples were taken at 12:00 h on Days 10,12,18,20,24, 27, 34 and 39 for the determination of melatonin concentrations. The implants were removed on 21 February (Day 27). Pouches were checked daily from Day 26 after removal of pouch young to Day 63 and females were inspected for signs of a mating plug.

In Exp. 2(b), 5 lactating females were maintained under conditions of natural temperature and photoperiod and pouch young were removed on 25 January 1985 (Day 0). On 5 February (Day 11), each female received a subcutaneous injection of $5 \mu \mathrm{g}$ melatonin in $0.5 \mathrm{ml}$ arachis oil ( $400 \mathrm{ng} / \mathrm{kg}$ body weight). The injections were administered for 10 days at 14:50 h, some $2.5 \mathrm{~h}$ before the mean dusk time. Pouches were checked daily from Day 26 to Day 58 after removal of pouch young and females inspected for signs of mating plugs.

Experiment 3: the effect of exposure to long days followed by short days 1-2 months after the winter solstice. Four adult lactating females were moved from conditions of natural photoperiod and temperature on 21 January 1985 to individual pens within a light chamber and pouch young were removed (Day 0 ). The duration of daylength was set at $15 \mathrm{~h}$ light: $9 \mathrm{~h}$ dark (15L:9D), some $5 \mathrm{~h} 3 \mathrm{~min}$ greater than the estimated natural photoperiod at that time of year. At 4 weeks after the start of the experiment (Day 28;18 February) the animals were removed from the light chamber and maintained in the presence of a male under conditions of natural photoperiod an estimated reduction in daylength of $3 \mathrm{~h} 42 \mathrm{~min}$. Pouches were inspected daily for newborn young and the presence of mating plugs from Day 25 to Day 60 and twice weekly from Day 60 to Day 85 .

Experiment 4: the effect of daylength reductions 5 months after the winter solstice. Pouch young were removed from 6 lactating females housed under natural conditions of photoperiod and temperature on 3 May 1985 (Day 0). On 23 May (Day 20), the animals were moved to an artificial photoperiod of 12L:12D in a light chamber (lights on 05:00 h GMT), a reduction of $5 \mathrm{~h}$ from the natural photoperiod. On 3 June (Day 31), animals were moved back to the natural photoperiod. Pouches were checked daily from Day 26 to Day 63 and all females were inspected for signs of a mating plug. Serial blood samples for the determination of melatonin concentrations were collected on $22 \mathrm{May}$ at $12: 30 \mathrm{~h}$ and then at 2-h intervals from 16:30 to $08: 30 \mathrm{~h}$ the following day. On 28 May samples were taken at $12: 30 \mathrm{~h}, 15: 30 \mathrm{~h}$ and then at 2 -h intervals from $18.30 \mathrm{~h}$ to $08.30 \mathrm{~h}$ the following day. 
Experiments 5(a) and 5(b): the effect of melatonin 5 months after the winter solstice. In Exp. 5(a), 4 wallabies were anaesthetized and melatonin implants (described above) were inserted on 21 May (Day 0 ). The 4 animals used in this experiment were also used in Exp. 2(a) (see above). The implants were removed on 6 June (Day 16). In Exp. 5(b), 10 wallabies were divided into two groups. Five animals received a daily subcutaneous injection of melatonin (dose and vehicle described above) between 21 and 31 May 1985. Melatonin was injected at 19:45 h GMT, 2 h before dusk. The 5 animals used in this experiment were also used in Exp. 2(b). The remaining 5 control animals received an injection of the oil vehicle at the same time of day as treatment animals. In Exp. 5(b), serial blood samples were collected from treatment animals on 22 May at 17:00, 18:00, 19:00, 19:30, 20:00, 20:30, 21:30, 22:30 and 23:30 h. Control animals were blood sampled on 28 May at 13:00, 16:30, 19:00, 21:00, 23:00, 01:00, 03:00, 04:30, 06:30 and 08:30 h.

Blood sampling and hormone determination. Blood samples were collected by puncture of the lateral tail vein. Samples for the determination of progesterone concentrations were collected on ice. All samples were centrifuged within $1 \mathrm{~h}$ of collection and plasma was stored at $-20^{\circ} \mathrm{C}$. For progesterone determination, plasma was extracted with $n$-hexane and hormone concentration was measured by radioimmunoassay as previously described (Curlewis $e t$ al., 1987). The limit of detection of the assay was $20 \mathrm{pg} / \mathrm{ml}$ plasma and the inter- and intra-assay coefficients of variation were 14.2 and $5.8 \%$ respectively. Melatonin concentrations were determined by direct radioimmunoassay using the method of Webley et al. (1985) as modified by Curlewis \& Loudon (1987). The limit of detection of the assay was $5 \mathrm{pg} / \mathrm{ml}$ plasma. The intra-assay coefficients of variation, assessed by repeated assay in duplicate of 2 pools of plasma containing 9 and $23 \mathrm{pg}$ melatonin $/ \mathrm{ml}$ were $21 \cdot 5$ and $4 \cdot 1 \%$ respectively $(n=8)$. The inter-assay coefficient of variation, determined from measurement of the melatonin concentration in 3 pools of plasma containing $7 \cdot 5,25$ and $90 \mathrm{pg} / \mathrm{ml}$ was $19 \cdot 5,16 \cdot 3$ and $12 \cdot 4 \%$ respectively $(n=10)$.

\section{Results}

\section{Reproductive activity: experiments 1-2 months after the winter solstice}

The results of Exps 1-3 are summarized in Table 1. In Exp. 1(a), 3 out of 6 animals gave birth 28,28 and 33 days after the removal of pouch young, indicating that they were not in a state of seasonal quiescence when pouch young were removed. Of the remaining 3 , none gave birth or were mated following the reduction in daylength 2 weeks after removal of pouch young. In Exp. 1(b), two of the control animals underwent a single reproductive cycle after removal of pouch young; the remaining 4 animals showed no evidence of reproductive activity based on progesterone determination and the absence of births (Table 1). None of the 6 treatment animals showed evidence of reproductive cycles after removal of young or the reduction in daylength. From early February to the end of the sampling period in late March, progesterone concentrations remained below $300 \mathrm{pg} / \mathrm{ml}$ plasma, indicative of a quiescent CL (Curlewis et al., 1987). In Exp. 2(a), 1 animal gave birth 28 days

Table 1. The interval (days) to birth and oestrus in Bennett's wallabies after removal of pouch young (RPY) and treatment with changes in photoperiod, melatonin or vehicle in February and May

\begin{tabular}{|c|c|c|c|c|c|c|c|}
\hline \multirow[b]{2}{*}{ Experiment } & \multirow{2}{*}{$\begin{array}{l}\text { No. of } \\
\text { animals }\end{array}$} & \multicolumn{2}{|c|}{$\begin{array}{l}\text { Interval from RPY } \\
(=\text { Day } 0) \text { to: }\end{array}$} & \multicolumn{2}{|c|}{$\begin{array}{l}\text { Interval from daylength } \\
\text { change (= Day } 0) \text { to: }\end{array}$} & \multicolumn{2}{|c|}{$\begin{array}{c}\text { Interval from start of } \\
\text { melatonin or vehicle }(=\text { Day } 0) \text { to: }\end{array}$} \\
\hline & & Birth & Oestrus & Birth & Oestrus & Birth & Oestrus \\
\hline \multicolumn{8}{|l|}{ February } \\
\hline $1 \mathrm{a}$ & 6 & $28,28,33$ & $\mathbf{a}$ & NR & $\mathrm{a}$ & & \\
\hline lb Treatment & 6 & NR & NR & NR & NR & & \\
\hline lb Control & 6 & 27,28 & $\mathbf{a}$ & & & NR & NR \\
\hline $2 a$ & 6 & 28,34 & 28,34 & & & NR & NR \\
\hline $2 \mathrm{~b}$ & 5 & NR & NR & 29,31 & $32^{\mathrm{c}}, 59^{\mathrm{c}}$ & & \\
\hline \multicolumn{8}{|l|}{ May } \\
\hline 4 & 6 & & & $29,31,31$ & $29,31,31^{\mathrm{c}}$ & & \\
\hline $5 a$ & 4 & & & & & $28,30,30^{\mathrm{b}}$ & 28,30 \\
\hline $5 \mathrm{~b}$ Treatment & 5 & & & & & 32,33 & $32,33,34^{\mathrm{c}}$ \\
\hline 5b Controls & 5 & & & & & NR & NR \\
\hline
\end{tabular}

NR, no response to treatment: $a$, data not obtained; $b$, birth but not mating; $c$, mating but no birth. 

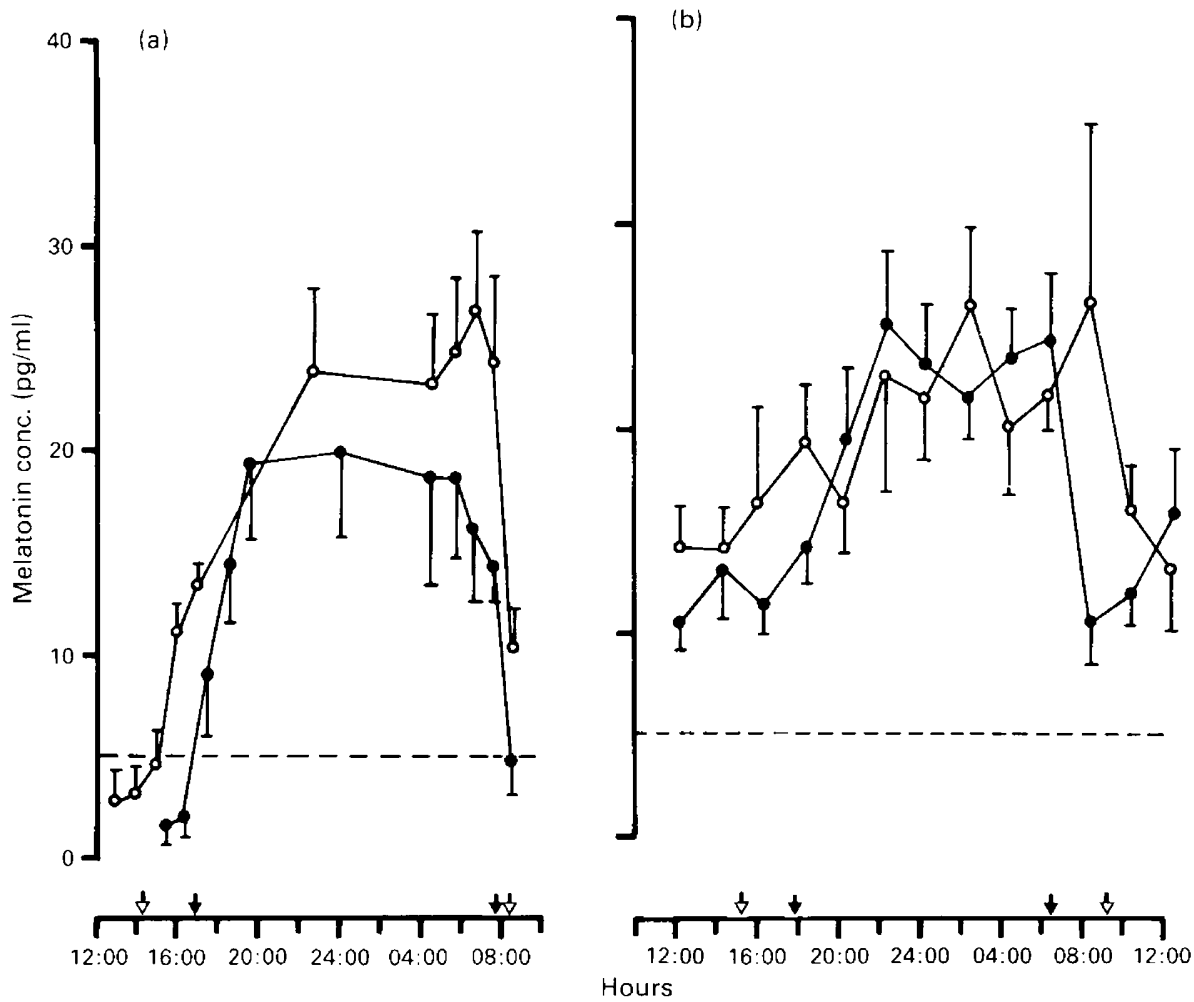

Fig. 2. Plasma melatonin concentrations for female wallabies on an artificial photoregimen which simulates natural daylength $(\bullet)$ and extended duration of night $(O)$ in (a) Exp 1(a) and (b) Exp. 1(b). The times of the onset of dawn and dusk are shown as arrows with simulated natural daylengths and increased dark phase as closed and open arrows respectively. The broken line indicates the limit of sensitivity of the assay. Animals were subjected to 3 or $5 \mathrm{~h}$ increase in night length.

and another 34 days after removal of pouch young. The remaining 4 animals showed no evidence of reproductive activity. In $\operatorname{Exp} 2$ (b) no animals showed any evidence of reproductive activity up to the end of the observation period. In Exp. 3, births $(N=2)$ or oestrus $(N=1)$ occurred within 33 days after the change from 15L:9D to natural daylength and the remaining animal was observed to have a mating plug 59 days after this transition. This last interval is approximately equivalent to two non-pregnant cycles in this species (Merchant \& Calaby, 1981; Curlewis et al., 1987).

\section{Reproductive activity: experiments 5 months after the winter solstice}

The results of Exps 4 and 5 are summarized in Table 1. In Exp. 4, 4 out of 6 animals showed clear evidence of reproductive activity (based on the presence of a newborn pouch young or a mating plug) within 32 days after the reduction in daylength. The remaining 2 animals were not observed to be mated or give birth. In Exps 5(a) and 5(b), 3 out 4 and 3 out of 5 animals either gave birth or exhibited oestrus within 35 days from the start of treatment with melatonin implants or injections respectively (see Table 1). None of the 5 control animals treated with vehicle alone gave birth, and in these animals births did not occur until the onset of the normal breeding season, with births occurring between 30 July and 2 September. 


\section{Melatonin concentrations in plasma}

Experiments 1-2 months after the winter solstice. The plasma melatonin concentrations of animals exposed to a reduction in photoperiod in January 1985 and 1986 are shown in Figs 2(a) and 2(b). After exposure to simulated natural and to reduced photoperiods in Exp. 1(a), melatonin concentrations were low in the 2 samples taken before dark; in the dark phase, mean values were significantly higher than those in the light phase during simulated and reduced photoperiods $(P<0.01$, Student's $t)$. Although there was no significant effect of treatment on peak night-time levels, the timing of the onset of the rise in melatonin was significantly advanced $(P<0 \cdot 01$, Student's $t$, simulated natural $v s$ reduced photoperiod, 15:30 and 16:30 h) In Exp. 1(b), concentrations showed a less substantial change with the onset of darkness. Mean night-time values were significantly higher $(P<0.05)$ than the daytime levels during simulated natural photoperiods $(21.8 \pm 1.5 \mathrm{vs} 12.3 \pm 1.4 \mathrm{pg} / \mathrm{ml}$ respectively) but there was no significant ( $P>0 \cdot 1$, Student's $t$ ) diurnal change in melatonin concentrations in animals exposed to an extended night. Melatonin concentrations in those animals that received implants in February (Exp. 2a) were $23.5( \pm 4.8)$ and $22.3( \pm 3 \cdot 2) \mathrm{pg} / \mathrm{ml}$ respectively before the insertion of the implants. Values rose to $207( \pm 13 \cdot 7) \mathrm{pg} / \mathrm{ml}$ after insertion of the implants and there was no significant change in melatonin concentration for the three samples collected over the 6-day sampling period.

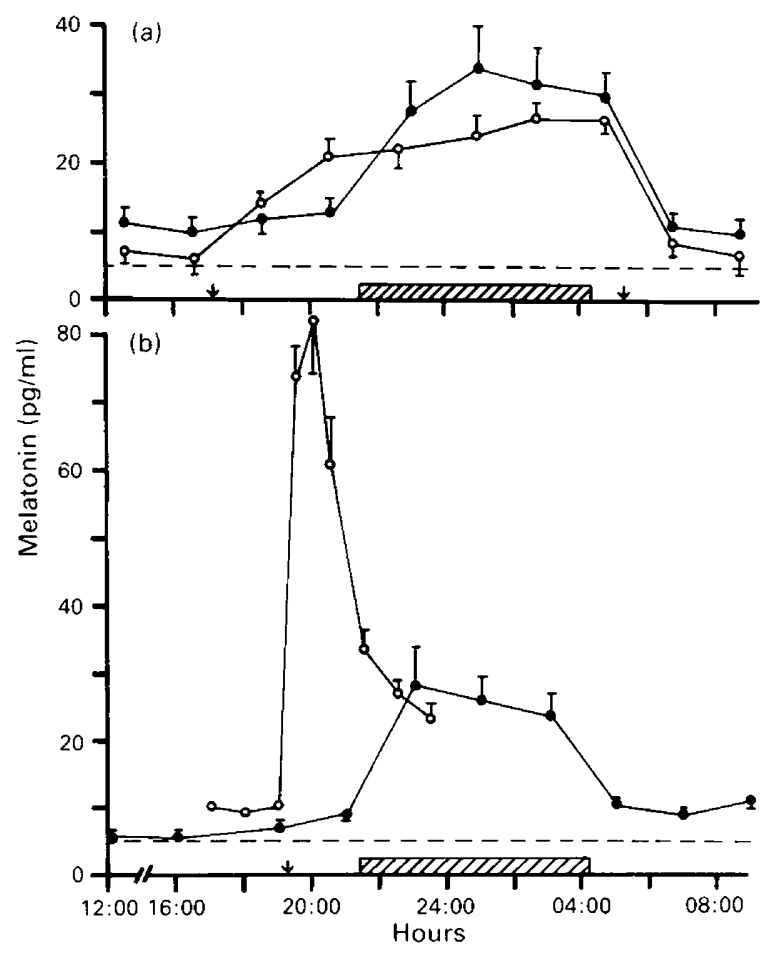

Fig. 3. Plasma melatonin concentrations for (a) 6 animals maintained under natural photoperiod ( $22 \mathrm{May}$, closed circles) and 5 days after a $5 \mathrm{~h}$ reduction in the duration of the light phase (open circles) in Exp. 4, and (b) for 5 adult females maintained under natural photoperiod (22 May, closed circles) and of a further 5 females treated with a $5 \mu \mathrm{g}$ injection of melatonin $2 \mathrm{~h}$ before the onset of dusk (open circles) in Exp. 5(b). Natural dawn and dusk are indicated by the stippled areas and the times of artificial dawn and dusk and injection with melatonin are shown by an arrow. The broken line indicates the limit of the sensitivity of the assay. 
Experiments 5 months after the winter solstice. The plasma melatonin concentrations of animals treated with a reduction in photoperiod in May (Exp. 4) are shown in Fig. 3(a). Under natural photoperiod, levels remained at $10-12 \mathrm{pg} / \mathrm{ml}$ for the 6 samples collected during daylight hours. Night-time concentrations rose to over $30 \mathrm{pg} / \mathrm{ml}$. A $5 \mathrm{~h}$ increase in night length was associated with a clear increase in the duration of secretion of melatonin. In the 4 samples collected in the light phase, concentrations were below $10 \mathrm{pg} / \mathrm{ml}$, while those collected during the dark phase rose to a mean of $22.3( \pm 1.9) \mathrm{pg} / \mathrm{ml}$. These values were not significantly lower than those measured in the dark phase under natural photoperiod $(P>0 \cdot 1$, Student's $t)$.

In animals injected with melatonin, plasma concentrations measured $15 \mathrm{~min}$ after injection were significantly increased relative to controls $(P<0.01$, Fig. 3b). By $4 \mathrm{~h}$ after injection, concentrations were similar to the night-time values seen in the control animals but significantly higher than those before injection.

\section{Discussion}

The results presented here demonstrate that, in early seasonal quiescence when natural photoperiod is still short, the reproductive axis of the Bennett's wallaby is refractory to the effects of a reduction in daylength. In this species, seasonal quiescence starts 10 weeks after the winter solstice (Curlewis et al., 1987) and in some females from which pouch young were removed in January, births occurred 27-35 days later, indicating that these animals were not yet in seasonal quiescence at the time of removal of pouch young. In those animals that were in seasonal quiescence in January and February, treatment with a reduction in photoperiod (Exps 1a \& 1b) in February was not followed by termination of quiescence. This was demonstrated in consecutive years for 3 and 6 animals. In contrast, an artificial reduction in daylength 5 months after the winter solstice, when natural daylength is long, resulted in the termination of quiescence in 4 out of 6 animals, with births or mating occurring 29-31 days after exposure to short days. In the remaining 2 females, which did not mate or give birth, it was not possible to establish reproductive status since blood samples were not collected for the determination of progesterone.

In the tammar wallaby, transfer from long to short daylengths also results in the termination of quiescence. However, in experiments on the tammar, animals were pre-exposed to artificial long days before the reduction in daylength (Sadleir \& Tyndale-Biscoe, 1977; Hinds \& den Ottolander, 1983; McConnell \& Tyndale-Biscoe, 1985). In the Bennett's wallaby, exposure to long daylengths after the winter solstice may be required before animals can respond to short daylengths. Indeed, in Exp. 3 exposure to 4 weeks of long days in early February followed by a reduction of $3 \mathrm{~h} 40 \mathrm{~min}$ daylength resulted in the termination of quiescence at a time of year when animals maintained on natural daylengths were insensitive to similar (Exp. 1a) or greater (Exp. 1b) reductions in photoperiod.

Measurements of plasma melatonin concentrations in animals exposed to a reduced daylength in early quiescence (Exp. la) indicate that the duration of secretion was extended by exposure to a $3 \mathrm{~h}$ increase in the length of the night. In the second year (Exp. 1(b)) the concentrations of melatonin showed a poor relationship to the light-dark cycle and on $5 \mathrm{~h}$ extended nights there was no evidence of a nocturnal rise. We have no explanation for this anomalous result. These data notwithstanding, the results from Exp. 1(a) indicate that, in terms of melatonin secretion, the Bennett's wallaby is capable of responding to an abnormally short day since the duration of melatonin secretion was extended by the treatment. Artificial reductions in the length of the day in May also resulted in a significant extension of the duration of melatonin secretion (Fig. 3a) and the termination of quiescence (Table 1). Therefore, although this species is able to extend the duration of melatonin secretion in response to reductions in daylength from both long and short daylengths, termination of quiescence only occurs when daylength is reduced from long to short days.

Results from experiments with melatonin in early seasonal quiescence are consistent with the hypothesis that animals are also refractory to treatment with melatonin at this time of year. Melatonin 
implants or late afternoon injections were not effective in terminating seasonal quiescence when administered 1-2 months after the winter solstice. In contrast, treatment 5 months after the winter solstice (by subcutaneous implant or daily injection $2 \mathrm{~h}$ before dusk), resulted in the termination of quiescence with births and matings 28-34 days after the start of treatment, some 1-3 months before births occurred in the control animals. In the absence of data on progesterone concentrations, we are unable to determine the reproductive response of those animals which failed to give birth or display oestrus. The plasma melatonin profiles of animals injected with melatonin $(400 \mathrm{ng} / \mathrm{kg}$ body weight) were clearly elevated for a longer period than in control animals (see Fig. 3). The results of treatment with melatonin in May confirm the earlier results of Loudon et al. (1985) for this species and are similar to data published on the tammar wallaby for the action of melatonin implants or daily injections before dusk in terminating seasonal quiescence (Renfree \& Short, 1984; McConnell \& Tyndale-Biscoe, 1985). It is clear from the data presented here that the reproductive response to injections of melatonin before dusk and implants which continuously release melatonin are similar despite obvious differences in the profiles of melatonin from the two treatments. In the experiments reported here, the interval from the onset of treatment to birth was 2-6 days greater than the normal interval from the removal of pouch young to birth in the breeding season. This is similar to the interval reported for the tammar by McConnell \& Tyndale-Biscoe (1985) but less variable than the interval previously quoted by Loudon et al. (1985) for the effect of melatonin implants in Bennett's wallabies.

It has been suggested that the tammar wallaby needs to experience an increase in the duration of melatonin secretion in order to terminate seasonal quiescence (McConnell \& Tyndale-Biscoe, 1985; McConnell et al., 1986) and that the quiescent CL may be reactivated in response to the decline in photoperiod 2 weeks after the summer solstice (Sadleir \& Tyndale-Biscoe, 1977; Tyndale-Biscoe $e t$ al., 1986). In contrast, the results presented here suggest that the response of the Bennett's wallaby to a reduction in daylength or melatonin treatment depends upon prior exposure to a long-day stimulus. Our data indicate that the ability of seasonal wallabies to respond to reductions in daylength may depend critically upon previous photoperiodic history and that a change in melatonin secretion per se does not necessarily result in the termination of seasonal quiescence.

Refractoriness to short daylengths and melatonin has been widely reported for seasonally breeding eutherian mammals. In the Syrian hamster, a long-day breeder, the breeding season begins spontaneously at the normal time of year in animals maintained in short daylengths and the transition from anoestrus to breeding can occur without exposure to long daylength (Turek \& Campbell, 1979; Reiter, 1980; Bartke \& Parkening, 1981). When in a short-day refractory state, however, hamsters are incapable of responding to melatonin (Turek \& Losee, 1978; Bittman, 1978). In sheep, short-day breeders, prolonged exposure to winter solstice daylengths has no effect on the timing of termination of the breeding season (Robinson \& Karsch, 1984) and the animal can be said to terminate breeding as a result of refractoriness to short daylengths. In the pinealectomized ewe, prolonged infusions of melatonin designed to mimic the pattern of secretion normally observed under short days eventually result in the termination of reproductive activity and refractoriness to a previously inductive melatonin signal (Karsch et al., 1986). These studies all indicate that changes in reproductive state will occur independently of a change in the circadian pattern of melatonin secretion. Here, we have demonstrated that females do not respond to short days or the melatonin signal in early reproductive quiescence. It remains to be established whether the natural transition from lactational to seasonal quiescence occurs due to refractoriness to the short daylengths of mid-winter or to a direct response to increasing daylengths some 6-8 weeks after the winter solstice.

We thank Alison White and Anne Coleman for assistance with this work; Alison Beasey for help with capture and management of animals; the staff of the animal hospital at the Zoological Society of London for providing space and facilities for the manipulations of photoperiod and for the husbandry of the animals while in this facility; and Dr John Barber, Department of Visual 
Optics, City University, London, for the measurements of illuminance. The project was supported by a grant from the S.E.R.C. of the U.K.

\section{References}

Adam, C.L. \& Atkinson, T. (1984) Effect of feeding melatonin to red deer (Cervus elaphus) on the onset of the breeding season. J. Reprod. Fert. 72, 463-466.

Andrewartha, H. \& Barker, S. (1969) Introduction to a study of the ecology of the Kangaroo Island wallaby, Protemnodon eugenii (Desmarest) within Flinders Chase, Kangaroo Island, South Australia. Trans. Roy. Soc. S. Australia 93, 127-132.

Arendt, J., Symons, A.M., Laud, C.A. \& Pryde, S.J. (1983) Melatonin can influence the early onset of the breeding season in the ewe. J. Endocr. 97, 395-400.

Bartke, A. \& Parkening, T.A. (1981) Effects of short photoperiod on pituitary and testicular function in the Chinese hamster, Cricetulus griseus. Biol. Reprod. 25, 958-962.

Berger, P.J. (1966) Eleven month 'embryonic diapause' in a marsupial. Nature, Lond. 211, 435-436.

Bittman, E.L. (1978) Hamster refractoriness: the role of insensitivity of pineal target tissues. Science, N.Y. 202, 648-650.

Bubenik, G.A. (1983) Shift of seasonal cycle in whitetailed deer by oral administration of melatonin. $J$. exp. Zool. 225, 155-156.

Curlewis, J.D. \& Loudon, A.S.I. (1987) The effect of changing photoperiod on the peripheral plasma melatonin concentration of the Bennett's wallaby (Macropus rufogriseus rufogriseus). J. Pineal Res. (in press).

Curlewis, J.D., White, A.S., Loudon, A.S.I. \& McNeilly, A.S. (1986) The effects of lactation and season on plasma prolactin concentrations and bromocriptine during lactation in the Bennett's wallaby (Macropus rufogriseus rufogriseus). J. Endocr. 110, 59-66.

Curlewis, J.D., White, A.S. \& Loudon, A.S.I. (1987) The onset of seasonal quiescence in the Bennett's wallaby (Macropus rufogriseus rufogriseus). J. Reprod. Fert. 80, 119-124.

English, J., Poulton, A.L., Arendt, J. \& Symons, A.M. (1986) A comparison of the efficiency of melatonin treatments in advancing oestrus in ewes. $J$. Reprod. Fert. 77, 321-327.

Fleming, D., Cinderey, R.N. \& Hearn, J.P. (1983) The reproductive biology of Bennett's wallaby (Macropus rufogriseus rufogriseus) ranging free at Whipsnade Park. J. Zool., Lond. 201, 283-291.

Flint, A.P.F. \& Renfree, M.B. (1982) Oestradiol-17ß in the blood during seasonal reactivation of the diapausing blastocyst in a wild population of tammar wallabies. J. Endocr. 95, 293-300.

Hinds, L.A. \& den Ottolander, R.C. (1983) Effect of changing photoperiod on peripheral plasma prolactin and progesterone concentration in the tammar wallaby (Macropus eugenii). J. Reprod. Fert. 69, $631-639$.

Karsch, F.J., Bittman, E.L., Robinson, J.E., Yellon, S.M., Wayne, N.L. Olster, D.L. \& Kaynard, A.H. (1986) Melatonin and refractoriness: loss of response to the melatonin signal leads to seasonal reproductive transitions in the ewe. Biol. Reprod. 34, 265-274.

Kennaway, D.J., Gilmore, T.A. \& Seamark, R.F. (1982) Effects of melatonin feeding on serum prolactin and gonadotrophin levels and the onset of seasonal estrous cyclicity in sheep. Endocrinology 110, 1766-1772.

Lincoln, G.A. \& Ebling, F.J.P. (1985) Effect of constant release implants of melatonin on seasonal cycles in reproduction, prolactin secretion and moulting in rams. J. Reprod. Fert. 73, 241-253.

Lincoln, G.A., Fraser, H.M. \& Fletcher, T.J. (1984) Induction of early rutting in male red deer (Cervus elaphus) by melatonin and its dependence on LHRH. J. Reprod. Fert. 72, 339-342.

Loudon, A.S.I., Curlewis, J.D. \& English, J. (1985) The effect of melatonin on the seasonal embryonic diapause of the Bennett's wallaby (Macropus rufogriseus rufogriseus). J. Zool., Lond. 206, 35-39.

McConnell, S.J. \& Tyndale-Biscoe, C.H. (1985) Response in peripheral plasma melatonin to photoperiod change and the effect of exogenous melatonin on seasonal quiescence in the tammar (Macropus eugenii). J. Reprod. Fert. 73, 529-538.

McConnell, S.J., Tyndale-Biscoe, C.H. \& Hinds, L.A. (1986) Change in duration of elevated concentrations of melatonin is the major factor in photoperiod response of the tammar. Macropus eugenii. J. Reprod. Fert. 77, 623-632.

Merchant, J.C. (1979) The effect of pregnancy on the interval between one oestrus and the next in the tammar wallaby (Macropus eugenii). J. Reprod. Fert. 73, 529-538.

Merchant, J.C. \& Calaby, J.H. (1981) Reproductive biology of the red-necked wallaby (Macropus rufogriseus banksianus) and Bennett's wallaby (M.r.rufogriseus) in captivity. J. Zool., Lond. 194, 203-217.

Nett, T.M. \& Niswender, G.D. (1982) Influence of exogenous melatonin on seasonality of reproduction in sheep. Theriogenology 17, 645-651.

Nowak, R. \& Rodway, R.G. (1985) Effect of intravaginal implants of melatonin on the onset of ovarian activity in adult and prepubertal ewes. J. Reprod. Fert. 74, 287-293.

Reiter, R.J. (1980) The pineal and its hormones in the control of reproduction in mammals. Endocr. Rev. 1, $109-131$.

Renfree, M.B. \& Short, R.V. (1984) Seasonal reproduction in marsupials. In Endocrinology 1984, pp. 789-792. Eds F. Labrie \& L. Proulx. Excerpta Medica, Amsterdam.

Robinson, J.E. \& Karsch, F.J. (1984) Refractoriness to inductive daylengths terminates the breeding season of the Suffolk ewe. Biol. Reprod. 31, 656-663.

Sadleir, R.M.F.S. \& Tyndale-Biscoe, C.H. (1977) Photoperiod and the termination of embryonic diapause in the tammar wallaby (Macropus eugenii). Biol. Reprod. 16, 605-608. 
Turek, F.W. \& Campbell, C.S. (1979) Photoperiodic regulation of neuroendocrine-gonadal activity. Biol. Reprod. 20, 32-50.

Turek, F.W. \& Losee, S.H. (1978) Melatonin-induced testicular growth in golden hamsters maintained in short days. Biol. Reprod. 18, 299-305.

Tyndale-Biscoe, C.H., Hinds, L.A. \& McConnell, S.J. (1986) Seasonal breeding in a marsupial: opportunities of a new species for an old problem Recent Prog. Horm. Res. 42, 471-512.
Webley, G.E., Mehl, H. \& Willey, K.P. (1985) Validation of a sensitive direct assay for melatonin for investigation of circadian rhythms in different species. $J$. Endocr. 106, 387-394.

Received 3 April 1987 